\title{
Use of peripheral vessels for exchange transfusion
}

\author{
T F Fok, L Y So, K W Leung, W Wong, C S Feng, S S Tsang
}

\begin{abstract}
During a five and a half year period, exchange transfusions were performed through the peripheral vessels in 201 of the 214 infants (94\%) who required either double volume or partial plasma exchange transfusions. Peripheral vessel exchange transfusion is simple, practicable, and safe with few complications. Technical difficulties in catheterising the peripheral artery and vein may be overcome by using a 24 gauge catheter, which causes no more catheter induced haemolysis than standard umbilical catheters.
\end{abstract}

To avoid the complications of exchange transfusions done by the conventional 'push pull' technique through the umbilical vein, ${ }^{12}$ an alternative technique using the peripheral vessels was successfully attempted in selected infants. $^{3-5}$ Since the opening of our neonatal unit in 1984 we have routinely used this technique on all infants requiring exchange transfusion. This report reviews our five and a half year experience with the technique in 201 infants.

\section{Patients and methods}

The case notes of all infants who received exchange transfusions between April 1984 and October 1989 were reviewed. During this period a total of 87 newborn infants with neonatal hyperbilirubinaemia received double volume exchange transfusions. During the same period partial exchange transfusions with plasma were carried out in 127 infants with polycythaemia. Attempts were made to carry out the exchange through a peripheral vessel in all except three premature infants who had indwelling umbilical arterial catheters already in place. The indication for exchange transfusion in infants born at full term was a serum bilirubin concentration of more than $340 \mu \mathrm{mol} / \mathrm{l}$. In premature infants, exchange transfusions were carried out when the serum bilirubin concentrations were lower depending on the gestational ages and birth weights. Indications for partial exchange transfusions were venous packed cell volume of over 0.70 in any infant, and symptoms related to hyperviscosity such as respiratory distress, lethargy, and excessive jitteriness in infants with venous packed cell volumes of $0 \cdot 60-0 \cdot 70$.

TECHNIQUE

A peripheral artery (radial or posterior tibial) was cannulated percutaneously with a 24 gauge Angiocath (Deseret Pharmaceutical) under aseptic conditions. Before each cannulation Allen's test was carried out to confirm the adequacy of collateral circulation of the cannulated limb. ${ }^{6}$ The course of the artery was located either by palpation or by transillumination with a fibreoptic light source. The catheter was connected to a syringe and three way stopcock so that blood could be withdrawn and discarded intermittently. A 22 gauge or 24 gauge catheter of a similar make was inserted aseptically into a superficial vein of another limb for the infusion of donor blood or plasma. Prewarmed blood in citrate-phosphate-dextrose not more than three days old was used for all exchange transfusions. Withdrawal and replacement of blood (or plasma) were carried out simultaneously at a rate of $5-10 \mathrm{ml} / \mathrm{min}$ by two different operators. As a prophylactic measure to prevent clotting during exchange transfusions, the arterial catheter was flushed intermittently with $1 \mathrm{ml}$ of heparinised saline ( 5 units $/ \mathrm{ml}$ ) after withdrawal of every $50 \mathrm{ml}$ of blood.

All exchanges were carried out under radiant warmers. The general condition of the infants and the circulation of the catheterised limbs were closely observed. Heart rate, respiratory rate, and skin temperature were continuously monitored electronically. The arterial blood pressure of infants receiving exchange transfusion was measured intermittently through the arterial line, which was connected to a pressure transducer by means of a three way stopcock. The catheters were removed at the end of the procedure, unless the infant had severe haemolytic hyperbilirubinaemia and was expected to require repeat exchange transfusions, in which case the catheters were kept patent by continuous infusion of heparinised saline (1 unit $/ \mathrm{ml})$ at a rate of $1 \mathrm{ml} /$ hour. Serum bilirubin concentration and packed cell volume were measured two hours after both exchange transfusion and partial exchange transfusion to determine the efficacy of the exchanges. Infants were observed in the neonatal unit for at least three days after the procedure.

EVALUATION OF CATHETER INDUCED HAEMOLYSIS The safety of using 22 gauge catheters from the point of view of catheter related haemolysis has been reported previously. ${ }^{3}$ As the narrower 24 gauge catheters were used in our patients, we compared the amount of haemolysis caused by these catheters with that caused by the standard 5 and 3.5 French gauge 'Argyle' umbilical vessel catheters (Sherwood Medical). Plasma 
Mean (SD) plasma haemoglobin concentrations of donor blood after infusion at three rates through a 24 gauge Angiocath, a 5 French gauge umbilical catheter and a 3.5 French gauge umbilical catheter ( $n=14$ in each group)

\begin{tabular}{|c|c|c|c|c|c|}
\hline \multirow{2}{*}{$\begin{array}{l}\text { Infusion rate } \\
(\mathrm{ml} / \mathrm{min})\end{array}$} & \multicolumn{3}{|c|}{ Plasma haemoglobin concentration $(\mathrm{g} / \mathrm{l})$} & \multicolumn{2}{|c|}{ Analysis of variance } \\
\hline & $\begin{array}{l}24 \text { gauge } \\
\text { Angiocath }\end{array}$ & $\begin{array}{l}5 \text { French } \\
\text { gauge umbilical } \\
\text { catheter }\end{array}$ & $\begin{array}{l}3 \cdot 5 \text { French } \\
\text { gauge umbilical } \\
\text { catheter }\end{array}$ & $F$ & p Value \\
\hline $\begin{array}{r}5 \\
10 \\
15\end{array}$ & $\begin{array}{l}0.44(0.08) \\
0.43(0.07) \\
0.45(0.08)\end{array}$ & $\begin{array}{l}0.44(0.08) \\
0.45(0.10) \\
0.43(0.08)\end{array}$ & $\begin{array}{l}0.45(0.11) \\
0.46(0.10) \\
0.49(0.09)\end{array}$ & $\begin{array}{l}0.14 \\
0.52 \\
1.65\end{array}$ & $\begin{array}{l}0 \cdot 87 \\
0 \cdot 60 \\
0 \cdot 20\end{array}$ \\
\hline
\end{tabular}

All values significantly greater than the mean $(\mathrm{SD})$ concentration before infusion of $0 \cdot 36(0 \cdot 05)$.

haemoglobin concentration estimated by the cyanmethaemoglobin method was used as the marker of haemolysis. ${ }^{7}$ Fourteen blood samples were drawn from five units of eight day old blood in citrate-phosphate-dextrose with known plasma haemoglobin concentrations. Each sample was then manually infused at three different infusion rates $-5,10$, and $15 \mathrm{ml} /$ minute-through each of these catheters. The plasma haemoglobin concentrations after infusion through each catheter at each rate were measured and compared with the preinfusion concentration by Student's $t$ test, and also among themselves by analysis of variance.

\section{Results}

During the study period peripheral vessel exchange was successfully carried out in 79 infants requiring exchange transfusion and 122 infants requiring partial exchange transfusion, giving an overall success rate of $95 \%$ (201 of 211). We had to resort to the umbilical route in five infants born at full term in whom cannulation of a peripheral artery was unsuccessful. Among those who had their exchanges by the peripheral route, eight (five receiving exchange transfusions and three receiving partial exchange transfusions) presented with respiratory distress and were given antibiotic prophylaxis before the exchange.

The group of infants receiving peripheral exchange transfusion had gestational ages ranging from $30 \cdot 1$ to $41 \cdot 2$ weeks, and birth weights ranging from 1370 to $4100 \mathrm{~g}$. Their serum bilirubin concentrations ranged from 299 to $459 \mu \mathrm{mol} / 1$ before exchange transfusion, and 128 to $240 \mu \mathrm{mol} / 1$ two hours afterwards. The mean drop in serum bilirubin concentration was $163 \mu \mathrm{mol} / \mathrm{l}$ (range $110-205$ ), or $45 \%$ of the concentration before exchange. The volume of donor blood exchanged varied from 300 to $600 \mathrm{ml}$ depending on the size of the infant. Most of the exchange transfusions were completed within 90 minutes (range 45-175, mean 82). One infant with glucose 6-phosphate dehydrogenase deficiency had three exchanges; two other infants with the same deficiency, and two with ABO incompatibility, required two exchanges each. The same arterial lines were used for the repeat exchanges.

The gestational ages and birth weights of the infants who received partial exchange transfusion by the peripheral route were $33 \cdot 1-42$ weeks, and $1720-4620 \mathrm{~g}$, respectively. Packed cell volumes before partial exchange transfusion ranged from 0.63 to 0.82 . All babies showed a satisfactory drop in packed cell volume of 0.07 to 0.25 (mean 0.19 ) to 0.49 to 0.64 two hours after the exchange. As the partial exchange transfusions required smaller volumes of blood $(24-100 \mathrm{ml})$, the time required for transfusion was only 5-30 minutes (mean 16).

There were no deaths, and the few complications mainly affected those who had had exchange transfusions. The arterial catheters became blocked in four infants and dislodged in two. Subcutaneous extravasation of infused blood occurred at the venous side in two infants. In all eight infants the exchange was completed after successful reinsertion of the catheters. One infant developed Escherichia coli septicaemia associated with a urinary tract infection two days after exchange transfusion. This infant was subsequently found to have bilateral grade III vesicoureteric reflux that later resulted in recurrent urinary tract infections.

The retrospective nature of this study did not allow us to analyse in detail the cardiorespiratory events that took place during the exchanges. We can only note that there were no appreciable untoward changes in heart rate, respiratory rate, and blood pressure during any of the procedures. Ischaemia of the catheterised limbs was not seen. All infants continued to be fed according to their routine schedule before and after the procedure. None developed any food intolerance or other abdominal complaints.

Results of the in vitro experiment on catheter induced haemolysis are shown in the table. We had used relatively old blood in the experiment, which should be more vulnerable to catheter induced mechanical damage. At each infusion rate all three catheters produced significant haemolysis as shown by an increase in plasma haemoglobin concentrations in the blood samples taken after infusion. There was, however, no significant difference in the plasma haemoglobin concentrations after infusion among the three types of catheter at each infusion rate, showing that the $\mathbf{2 4}$ gauge Angiocath did not cause more haemolysis than either the 5 or 3.5 French gauge umbilical catheters.

\section{Discussion}

Exchange transfusions using the umbilical vein or artery are associated with complications such as haemoperitoneum, ${ }^{8}$ intestinal perforation, ${ }^{9}$ necrotising enterocolitis, ${ }^{810}$ air embolism, ${ }^{2}$ portal hypertension, ${ }^{811}$ and introduction of infection from the umbilical stump. ${ }^{12}$ Gastrointestinal complications seem particularly common in polycythaemic infants treated with partial exchange transfusion by the umbilical 
route. ${ }^{13}$ Fluctuations in circulatory volume resulting from the conventional 'push-pull' technique have been associated with cardiovascular complications including sudden cardiac arrest, pulmonary oedema, bradycardia, ${ }^{15}$ and changes in cerebral blood flow and intracranial pressure. ${ }^{16} \mathrm{~A}$ double catheter technique using both the umbilical artery and vein for simultaneous withdrawal and replacement of blood has been described, ${ }^{17}$ but this method carries the risks of catheterisation of both the umbilical artery and the umbilical vein.

The peripheral vessels have been used as an alternative route for exchange transfusions in selected infants by previous workers. ${ }^{3-5}$ Our experience gives further evidence that the technique can be used routinely in most babies who require double volume or partial plasma exchange transfusion. Of our exchanges, $95 \%$ were successfully carried out by the peripheral route resulting in satisfactory drops in serum bilirubin concentrations in the hyperbilirubinaemic infants, and packed cell volumes in the polycythaemic infants. Apart from the six infants who required recatheterisation of the artery, none of our patients developed any complications associated with the procedure. The $E$ coli septicaemia that developed in one of the infants was probably related more to his urinary tract abnormality than to the exchange transfusion.

By avoiding the umbilical vessels, the technique should theoretically be associated with a reduction in risks of infection and intraabdominal complications. Removal and replacement of blood with blood or plasma take place simultaneously, thus minimising cardiovascular changes caused by fluctuations in circulatory volume. Throughout the procedure only the limbs need to be exposed and immobilised, and temperature control becomes less of a problem as the infants' clothing need not be removed. As gastrointestinal complications are not a problem, fasting of the infants before and after the procedure is unnecessary. Unlike the umbilical route, the peripheral route can be used in infants of any age, including those in whom the umbilicus has healed.

Success in carrying out peripheral vessel exchange transfusions depends largely on successful placement of the arterial catheter, which may be technically difficult especially in vigorous infants born at full term with relatively thick skin. In our experience, peripheral arterial cannulation with the $\mathbf{2 4}$ gauge catheter is much easier than with the 22 gauge catheter, ${ }^{3}{ }^{4}$ and is more secure than with the scalp vein needle that was used by previous workers. ${ }^{5}$ Despite its narrower lumen, we did not encounter any difficulties in withdrawal of blood and most of our double volume exchange transfusions could be completed within a reasonable time.

On the venous side we have used both the 22 gauge and 24 gauge catheters for plasma or blood replacement. The safety in using the 22 gauge catheter for blood infusions has been shown by Campbell and Stewart. ${ }^{3}$ Our in vitro study on catheter induced haemolysis shows that the 24 gauge catheter does not cause any more haemolysis than either the 5 or the 3.5 French gauge umbilical catheter.

Despite its practical and theoretical advantages, exchange transfusion though the peripheral vessels does not seem to have gained much acceptance by paediatricians since it was first described. Our experience shows that it is simple, practicable, and safe, with few complications. In the light of the existing evidence that both sick premature and healthy infants born at full term may develop complications when exchange transfusion is carried out by the umbilical route, ${ }^{12}$ we believe that using the peripheral route is one way to minimise iatrogenic risks and should be considered for all infants requiring exchange transfusion.

1 Keenan WJ, Novak KK, Sutherland JM, et al. Morbidity and mortality associated with exchange transfusion. Pediaand mortality associated with

2 Weldon VV, Odell GB. Mortality risk of exchange transfusion. Pediatrics 1968;41:797-801.

3 Campbell N, Stewart I. Exchange transfusion in ill newborn infants using peripheral arteries and veins. $f$ Pediatr 1979;94:820-2.

4 Srinivasan G, Shankar H, Yeh TF, Pildes RS. A critical care problem in neonates: exchange transfusions through peripheral artery. Crit Care Med 1980;8:338-40.

5 Scarcella A, Gambardella P. Partial exchange transfusion using peripheral vessels in polycythaemic newborn infants. Eur F Pediatr 1986;144:545-6.

6 Allen EV. Thromboangiitis obliterans: methods of diagnosis of chronic occlusive arterial lesions distal to the wrist with illustrative cases. Am $\mathrm{f} \mathrm{Med} \mathrm{Sci} \mathrm{1929;178:237-44.}$

7 Dacies JV, Lewis SM. Basic haematological techniques. In: Dacies JV, Lewis SM, eds. Practical haematology. 6th ed. Dacies JV, Lewis SM, eds. Practical haematology.

8 Touloukian RJ, Kadar A, Spencer RP. The gastrointestinal complications of neonatal umbilical venous exchange transfusion. A clinical and experimental study. Pediatrics 1973; 51:36-43.

9 Hilgartner MW, Lanzkowsky P, Lipsitz P. Perforation of small bowel and large intestine following exchange transfusion. Am $\mathcal{F}$ Dis Child 1970;120:79-81.

10 Joshi VV, Draper DA, Bates RD. Neonatal necrotizing enterocolitis. Occurrence secondary to thrombosis of abdominal aorta following umbilical arterial catheterization. Archives of Pathology 1975;99:540-3.

11 Oski FA, Allen DM, Diamond LK. Portal hypertension-a complication of umbilical vein catheterization. Pediatrics 1963;31:297-302.

12 Krauss AN, Albert RF, Kannan MM. Contamination of umbilical catheters in the newborn infant. $\mathcal{f}$ Pediatr 1970;77:965-9.

13 Black VD, Rumack CM, Lubchenco LO, Koops BL. Gastrointestinal injury in polycythemic term infants. Gediatrics 1985;76:225-31.

14 Aranda JV, Sweet AY. Alterations in blood pressure during exchange transfusion. Arch Dis Child 1977;52:545-8.

15 Hovi L, Siimes MA. Exchange transfusion with fresh heparinized blood is a safe procedure: experiences from 1069 newborns. Acta Paediatr Scand 1985;74:360-5.

16 Bada HS, Chua C, Salmon JH, Hajiar W. Changes in intracranial pressure during exchange transfusion. $\mathcal{F}$ Pediat 1979;94:129-32.

17 Martin JR. A double catheter technique for exchange transfusion in the newborn infant. New Zealand Medical fournal 1973;77:167-9. 